\title{
Una secuencia didáctica como experiencia para el desarrollo de prácticas de escritura auténtica ${ }^{1}$
}

\author{
Clara Emilia Calderón-Perilla* \\ Ulises Segura-Barón**
}

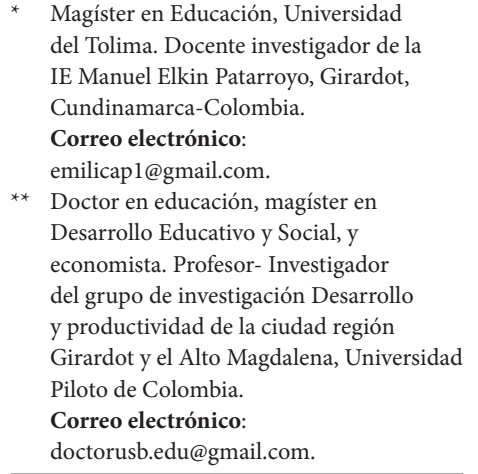

Recibido: 16 de julio del 2018

Aprobado: 25 de octubre del 2018

Cómo citar este artículo: Calderón-Perilla, Clara Emilia, Segura-Barón, Ulises. "Una secuencia didáctica como experiencia para el desarrollo de prácticas de escritura auténtica". Rastros Rostros 19.35

(2017): 1-14. Impreso. doi: https://doi. org/10.16925/2382-4921.2017.35.02

\section{Resumen}

Introducción: este artículo es resultado de la aplicación de una secuencia didáctica al grado once de la Institución Educativa Manuel Elkin Patarroyo de la ciudad de Girardot. En la ruta inicial de la secuencia didáctica los estudiantes realizaron actividades para motivar la escritura. En el desarrollo central de la secuencia surgió una novedosa narrativa a partir de la pregunta ¿cómo quieres que sea tu mundo después de tu graduación? El marco teórico se basa en las teorías de Sergio Tobón y Daniel Cassany, entre otros, como aporte actualizado a las necesidades de los procesos de producción textual escrita en el siglo XXI. Metodología: se fundamenta en el avance gradual de las actividades de lo elemental a lo complejo y, a su vez, son acompañadas por un proceso de evaluación formativa que facilitó el desarrollo de habilidades y que alcanzó importantes procesos de reflexión. Resultados: los textos se compilaron y se elaboró un libro con veintinueve autores, susceptible de ser publicado. Conclusiones: este conjunto de estrategias y procesos fortalecieron la competencia de producción textual escrita de los estudiantes, además de que se amplió la comprensión de su contexto gracias a una escritura auténtica.

Palabras clave: pre-escritura, pos-escritura, secuencia didáctica. 


\title{
A didactic sequence as experience for the development of authentic writing practices ${ }^{2}$
}

\begin{abstract}
Introduction: This article is the result of the application of a didactic sequence to the $11^{\text {th }}$ grade of the "Institución Educativa Manuel Elkin Patarroyo" of the city of Girardot. In the initial route of the didactic sequence the students carried out activities to motivate writing. At the heart of the development of the sequence, a novel narrative emerged from the question, "How do you want your world to be after your graduation?" The theoretical framework is based on the theories of Sergio Tobón and Daniel Cassany, among others, as an updated contribution to the needs of the processes of textual production written in the 21st century. Methodology: Activities were advanced gradually from the elementary to the complex and, in turn, are accompanied by a process of formative evaluation that facilitates the development of skills and achieves important reflections processes. Results: The texts were compiled and a book was prepared (ready for publication) with a total of twenty-nine authors. Conclusions: This set of strategies and processes strengthened the students' competence with the production of written text in addition to broadening their understanding of its context thanks to authentic writing.
\end{abstract}

Key words: pre-writing, post-writing, didactic sequence.

\section{Uma sequência didática como experiência para o desenvolvimento de práticas de escrita autêntica ${ }^{3}$}

\section{Resumo}

Introdução: o artigo é resultado da aplicação de uma sequência didática à última série da Instituição Educativa Manuel Elkin Patarroyo da cidade de Girardot. No início da sequência didática, os alunos fizeram atividades para motivar a escrita. No desenvolvimento central da sequência surgiu uma nova narrativa a partir da questão: como você quer que seu mundo seja depois da sua formatura? Partiu-se das teorias de Sergio Tobón e Daniel Cassany, entre outros autores, como insumo atualizado às necessidades dos processos de produção textual escrita no século XxI. Metodologia: fundamenta-se no avanço gradual das atividades do simples ao complexo e no acompanhamento de um processo de avaliação formativa que possibilitou u desenvolvimento de habilidades e importantes processos de reflexão. Resultados: compilaram-se textos e se criou um livro de 29 autores, com possibilidades de publicação. Conclusões: o conjunto de estratégias e processos fortaleceram a competência de produção textual escrita entre os alunos, além de que se acrescentou a compreensão do contexto a partir da escrita autêntica.

Palavras-chave: pre-escrita, pós-escrita, sequência didática.

$2 \quad$ This article is the result of the research Project entitled "Una secuencia didáctica como experiencia para el desarrollo de prácticas de escritura auténtica en el grado 11-4 de la institución educativa Manuel Elkin Patarroyo" of the "Universidad del Tolima", Colombia.

3 Artigo resultado do projeto de pesquisa "Uma sequência didática como experiência para o desenvolvimento de práticas de escrita autêntica na turma 11-4 da Instituição Educativa Manuel Elkin Patarroyo" da Universidade do Tolima, Colômbia. 


\section{Introducción}

Este artículo presenta los resultados de la investigación que se realizó: "una secuencia didáctica como experiencia para el desarrollo de prácticas de escritura auténtica en el grado once de la Institución Educativa Manuel Elkin Patarroyo de Girardot, Cundinamarca". Esta surgió tras continuos ejercicios de reflexión y debates académicos sobre los limitados procesos de escritura que desarrollaban los estudiantes de último grado de la institución educativa en 2015. Se trató de una experiencia aplicada en el aula escolar desde el área de español con el fin de fortalecer los procesos de escritura de la educación media.

Este artículo comienza con la presentación de los antecedentes en los que se hace énfasis en el interés por los procesos escriturales de los jóvenes en la educación media. Luego, se realiza el planteamiento del problema, las preguntas de la investigación y se presentan los objetivos, respectivamente. En seguida se presentan los aspectos metodológicos, posteriormente se trabajan los referentes teóricos y se da cuenta de la necesidad de escribir en la escuela, cómo se concibe la escritura en la educación media, para qué escribir, cómo evaluar la escritura en la educación media. A continuación, se exponen las tres fases de la secuencia y, finalmente, se presentan las conclusiones.

\section{Planteamiento del problema}

Los estudiantes de grado once de la Institución Educativa Manuel Elkin Patarroyo de la ciudad de Girardot, tienen desinterés por la lectura y mucho más con respecto a la actividad de la escritura. Los procesos de escritura los realizan por obligación, de afán, sin preocupación por la concordancia, tanto en género como en número, y con un descuido por el uso de la ortografía, la puntuación y el adecuado manejo de las mayúsculas. No les interesa identificar una idea central en los párrafos escritos y terminan copiando fragmentos de otros textos.

De esta forma, los estudiantes terminan entregando una producción textual incoherente y desarticulada, alejada de la unidad global que todo texto requiere para proyectar la intencionalidad del mismo. Lo anterior permite delimitar la existencia de una problemática muy común en la actualidad de la escuela: las prácticas de escritura no tienen sentido, ni significado para los estudiantes. Tal situación se debe a la concepción de la escritura desde la perspectiva gramatical, la cantidad y la transcripción. De ahí que sea necesario transformar las prácticas de escritura de la población seleccionada, para encontrar caminos que permitan resignificarla, como una actividad auténtica, significativa y real, que contribuye a su formación como sujetos críticos y políticos.

A partir de la problemática delimitada, surgió la siguiente pregunta de investigación: ¿cuáles son las características que permiten transformar las prácticas de escritura convencionales en el grado once de la Institución Educativa Manuel Elkin Patarroyo? Se entiende la transformación de las prácticas como una perspectiva originada a partir de un proceso común, pero que, por características metodológicas, se constituye en una nueva manera de desarrollar los procesos de aprendizaje, en este caso de la escritura. De este modo, se propone la secuencia didáctica como una estrategia metodológica que contribuye con la creación de escenarios e intencionalidades pedagógicas y busca, como objetivo principal, desarrollar prácticas de escritura auténtica con los estudiantes del grado once de la Institución Educativa Manuel Elkin Patarroyo de Girardot.

Esta pretensión es posible, solo si se replantean los sentidos e intereses que tiene que un adolescente escriba desde la escolaridad y si se conocen otras experiencias humanas que, a partir del lenguaje, contribuyan a reconocer en la escritura un elemento generador de pensamiento. Para tal fin, la secuencia didáctica permite adecuar las prácticas de escritura a la multiplicidad de intereses, capacidades y estilos que enmarcan las vivencias de los jóvenes, quienes, desde su propio universo, serán autores de la publicación de un libro como resultado final de la experiencia de escritura.

\section{Diseño metodológico}

La investigación fue de carácter descriptivo, los profesores Hernández et al. afirman que esta requiere una rigurosidad especial en torno al conocimiento del área que se investigue, con una profundidad que permita el desarrollo del proceso, aunando predicciones y observando el medio con un conocimiento que, asociado con la correlación de las variables de estudio, logre finalmente explicar estas relaciones. El diseño fue no experimental. Hernández et al. manifiestan que éste: "se realiza sin manipular deliberadamente variables" (189), dado que se trata de no hacerlas variar, sino de observar, percibir y determinar sus movimientos para luego poder 
realizar análisis correspondientes de los cambios que ocurren en su ambiente natural. La investigación también tuvo un enfoque cualitativo. Retomando a Hernández et al., el enfoque cualitativo se refiere a la comprensión y profundización de los fenómenos encontrados explorándolos desde la perspectiva de los participantes en su ambiente natural y en relación con el contexto. Así, el enfoque cualitativo se seleccionó buscando comprender la perspectiva de los estudiantes acerca de los fenómenos que los rodean. En relación con la población y muestra, se contó con una población compuesta por el número total de estudiantes del grado once de la Institución Educativa Manuel Elkin Patarroyo, es decir, 29 estudiantes, mientras que la muestra estuvo constituida por 27 estudiantes que efectivamente terminaron el curso académico.

\section{Justificación}

La justificación de la presente investigación se fundamenta en los siguientes aspectos: consolidado dentro del derecho a la educación, la producción textual, indirectamente, es también un derecho constitucional y, por lo tanto, una exigencia del Ministerio de Educación Nacional (MEN). El estudiante tiene el derecho constitucional de recibir la educación. Como receptor de estos procesos, el estudiante recibe de la práctica de escritura los siguientes beneficios:

- Escribir estructura el pensamiento porque el individuo se ve movido a otorgar sentido a la realidad que lo circunda produciendo un universo de significados.

- La actividad de escribir está marcada por diversas habilidades y destrezas como: la comprensión del valor del lenguaje, el desarrollo de procesos de autocontrol y corrección lingüística, procesos pragmáticos, semánticos y semióticos, entre otros. Estos son aspectos que posicionan al individuo en el lenguaje como única posibilidad de construcción de su propia identidad.

- La escritura es vital para iniciar los procesos académicos universitarios, lo que facilitará la fundamentación de estos porque permite la planificación de la acción en relación con los objetivos de su proyecto de vida.

- Escribir permite abordar otras líneas de pensamiento y acceder al entorno contextual porque se constituye en una herramienta fundamental para participar de los procesos culturales, mantener las relaciones sociales y construir espacios para el desarrollo personal y social.

- La elaboración textual no solo permite la producción del pensamiento científico, sino que le permite al individuo participar de los contextos políticos, culturales y sociales.

- La escritura le permite al individuo soñar y construir un universo imaginario donde puede convertir la dura realidad en una apacible irrealidad artística, que transforma la conciencia de sus congéneres, haciendo de la existencia vacía y cruel, un mundo mejor.

\section{Marco referencial}

Fundamentalmente, se hizo uso de la secuencia didáctica porque implica el abordaje de diversos aspectos de las competencias en sus tres saberes: aprender a ser, aprender a hacer y aprender a saber lo que permite articular la teoría con la práctica, y también porque da respuesta al reto requerido por el contexto de la investigación. Según Tobón et al., un aspecto fundamental de las secuencias didácticas destinadas a formar y evaluar competencias, desde la perspectiva socio-formativa, consiste en considerar un problema significativo y pertinente del contexto para orientar el proceso de mediación docente. Esto se debe al compromiso con que la educación no solo forme, sino que también sea un escenario social para actuar y contribuir a resolver los problemas del contexto.

Para este proyecto, el problema significativo y central es la deficiente producción textual de la mayoría de los estudiantes de grado once, pero también se vislumbra un segundo problema: el desconocimiento de los deseos, gustos y sueños de la juventud en general por parte del gobierno, representado en el Ministro de Educación y demás funcionarios, a quienes compete elaborar los Lineamientos y Estándares Básicos de Competencia Nacional. Es de dilucidar que para dar inicio a un proceso de enseñanza-aprendizaje se deben conocer los gustos, expectativas y deseos de los estudiantes para, partir de allí, construir y planear las prácticas de aula.

Con esta secuencia didáctica se amplía el escenario académico para cumplir, en primera instancia con unos objetivos establecidos por las competencias y, en segunda instancia, hacer un intento por llevar las preferencias y sueños de este grupo de estudiantes a la clase gubernamental, que han manifestado en repetidas ocasiones su interés por el bienestar 
y mejoramiento de la educación en el país. De esta manera, se ayudaría a resolver un problema real de la política y de la sociedad colombiana, pues una escuela que trasciende sus aulas para involucrar al estudiante y hacerlo conocedor y partícipe de los retos de su país es una escuela eficaz y pertinente.

\section{Habilidades para la producción textual.}

La secuencia didáctica, como estrategia valiosa, forma y desarrolla las competencias. Esta posibilidad es una fortaleza de este proyecto porque permite el abordaje de las dimensiones humanas. Uno de los conceptos de competencia de Tobón, es: "las competencias son procesos complejos de desempeño con idoneidad en un determinado contexto, con responsabilidad" (5) y al respecto Mercado Vargas y otro dice: "Ser competente es saber hacer y saber actuar entendiendo lo que se hace, comprendiendo cómo se actúa, asumiendo de manera responsable las implicaciones y consecuencias de las acciones realizadas y transformando los contextos a favor del bienestar humano" (Mercado Vargas y Mercado Vargas 73). Así que las competencias tienen implícito un contexto que promueve un desarrollo integral del estudiante y abarcan todas las dimensiones del ser humano en un momento dado. Dan cuenta de la responsabilidad como valor fundamental para un mundo diverso y cambiante como el de hoy.

Tobón recomienda, para la secuencia didáctica, considerar las competencias genéricas y las competencias específicas; las primeras entendidas como aquellas que son comunes para una comunidad y que, para Colombia, son las competencias ciudadanas, las competencias laborales generales y las competencias básicas y, las segundas, son las laborales específicas como las propias de cada profesión, que suponen un buen grado de especialización.

Para este proyecto, el desarrollo de las competencias lingüísticas y, a su vez, el de las competencias de la comunicación, son fundamentales en todos sus procesos. Estas son competencias transversales que se incluyen en las competencias genéricas; sin embargo, al interior de ellas aparecen competencias específicas. Las competencias éticas en el lenguaje son imprescindibles y ocuparán un lugar jerárquico en las mismas.

Otra habilidad importante son las actividades de aprendizaje, que son todas las acciones que los estudiantes deben realizar, son las acciones realizadas por ellos mismos con las que se van a enfrentar al contexto con el fin de conseguir lo que pretenden. Para realizarlas, el estudiante, inicialmente, ejecutará procesos mentales elementales como los de asociación, jerarquización, generalización, comparación, selección, elección, categorización, eliminación, etc., este momento será crítico porque el estudiante entrará a la zona de desarrollo próximo. Después podrá avanzar a los procesos mentales complejos como el análisis, comprensión, proposición, intuición, etc.

Precisamente, la concatenación de las actividades es el baluarte de la secuencia didáctica. Tobón, Pimienta y García afirman al respecto: "en la medida que las actividades se establezcan considerando su contribución al problema y tengan como referencia las competencias del contexto, entonces van a tener concatenación" (74. Así que se debe tener cuidado al planear la sucesión de las actividades para que, en esa secuencia, el avance se de en forma gradual desde lo concreto a lo complejo. Sintetizando, el énfasis está en la concatenación de las actividades y no como se hizo en el pasado, con el énfasis en los contenidos.

Por otro lado, se hace el proceso de evaluación presente y simultáneo en toda la ruta de la secuencia didáctica, además, la misma competencia así lo exige y es paralela, tal como Tobón lo manifiesta: "la evaluación de las competencias se propone como un proceso continuo que se hace a medida que se llevan a cabo las actividades de aprendizaje" (78). Como se plantea en el escenario teórico, y como se recomienda desde la misma secuencia didáctica, se partirá de una evaluación diagnóstica, se continuará con la evaluación formativa apoyada en la realimentación, se hará la evaluación sumativa, que para la institución educativa es pertinente para esta población de estudiantes, ya que está planteado en su currículo.

\section{Proceso metacognitivo.}

Para Tobón, Pimienta y García este proceso:

(...) consiste en orientar a los estudiantes para que reflexionen sobre su desempeño y lo autorregulen (es decir lo mejoren), con el fin de que puedan realizar un aprendizaje significativo y actúen ante los problemas, con todos los recursos personales disponibles. De esta manera la metacognición no consiste solo en tomar conciencia de cómo actuamos. (81)

Entonces, la metacognición ofrece esa mirada holística que también involucra al estudiante en la responsabilidad que conlleva la misma evaluación y su efecto. Para este proyecto, en las actividades de aprendizaje, se incluyeron: actividades de apertura, actividades de desarrollo y actividades de cierre. 


\section{Fases de la secuencia.}

Son tres fases que dan cuenta de esta secuencia didáctica:

a. Fase de apertura en la que se dará inicio al proyecto.

b. Fase de desarrollo.

c. Fase de cierre.

\section{Fase de apertura: buscando los caminos de la escritura}

En esta primera fase, llamada pre-escritura, se presenta al estudiante el proyecto como una propuesta general, teniendo en cuenta el contexto y, por supuesto, la problemática que, en primera instancia, es la necesidad de mejorar la producción de textos escritos. Después se dirá cuál fue la otra problemática que surgió, se acudirá necesariamente a unos referentes teóricos que han de dar fundamentación a este proyecto. De esta manera se le presentó a los estudiantes la posibilidad de realizar un proyecto para la elaboración de un libro con treinta autores, que serían ellos mismos. También se les hizo la pregunta formal de si aceptan hacer parte del proyecto. Tuvieron conocimiento de que el objetivo central del proceso de escritura, cuando esta debidamente guiado, contribuirá a mejorar sus habilidades. En esta fase se plantearon y se determinron las intencionalidades del docente, igualmente respondieron a preguntas como: ¿qué quiero?, ¿qué sé?, ¿qué me gustaría saber?, ¿qué considero que deben saber?, ¿qué necesito para que lo hagan?, ¿qué quieren ellos?

\section{Fase de desarrollo: somos escritores.}

Esta fase ocupó el mayor tiempo de la secuencia didáctica, aquí se concretó la ruta de aprendizaje y se desarrolló la mayor parte de las actividades. Son nueve encuentros que correspondieron a cuatro semanas y media, y que los estudiantes también conocieron. De igual manera, conocieron las competencias y cada uno tendría a mano su respectiva rúbrica. Desde la evaluación formativa se acompañaron todos los procesos con la realimentación. Se inició con un debate sobre la temática central a elegir para la construcción del libro con 30 autores. El docente presentó e indujo a los estudiantes para que escribieran sobre sus sueños en una nueva realidad. Se debió entablar una discusión con argumentos y razonamientos válidos para que la temática no terminara siendo impuesta. En el caso contrario se ajustaría la secuencia a la nueva temática que los estudiantes propusieran. Después se elaboraró un cuento colectivo, en el que cada estudiante escribió el inicio de un cuento e invitó a cada uno de sus compañeros a escribir un aporte a su cuento. De tal manera que, al terminar la actividad, se obtuvieron 29 cuentos con 29 autores.

\section{Fase de cierre: lectores de nuestros escritos.}

En esta fase se realizó una síntesis para recapitular y extractar lo relevante. En esta fue importante preguntarse: ¿qué competencias mejoró?, ¿qué competencias corrigió?, ¿cuál es el producto adicional?, ¿a qué conclusiones llegó? Ante estos cuestionamientos se dio la reflexión. Y a su vez, en este final se hizo la evaluación sumativa requerida tanto por el Sistema Institucional de Evaluación (sIEDES), como por el decreto 1290 del MEN.

Para el desarrollo de los procesos escriturales en educación media, es necesario reconocer el concepto de secuencia didáctica. Las secuencias didácticas son, sencillamente, conjuntos articulados de actividades de aprendizaje y evaluación que, con la mediación de un docente, buscan el logro de determinadas metas educativas, en consideración de una serie de recursos. También se tiene en cuenta el concepto de Zabala, para quien son un conjunto de actividades ordenadas, estructuradas y articuladas para la consecución de unos objetivos educativos que tienen un principio y un final conocidos, tanto por el profesorado como por el alumnado. Se observa en estos conceptos que las actividades, en la secuencia didáctica, son el foco en el que el estudiante ha de proyectarse para el logro de unos objetivos, pero estas actividades hacen parte de un todo, así que, por la misma razón, deben ser coherentes. Es vital tener en cuenta el grado de complejidad porque en el paso gradual de la dificultad que presenta la actividad, está el avance cognitivo. Hay que anotar que las actividades vinculan los conocimientos y las experiencias previas con el interrogante que, para este proyecto es ¿cómo se hace un libro? La secuencia didáctica admite cambios, y más, para este grupo heterogéneo. Esta característica invita a la flexibilidad en todos los momentos y componentes del aula de clase, el hilo conductor es el que permite consolidar la unidad de la secuencia.

El énfasis de la secuencia didáctica no está en las actividades en sí, sino en la sucesión de actividades entendido como un encadenamiento planificado de estas. Como ya se dijo con anterioridad, el objetivo 
es la elaboración de un libro para publicarlo. De esta manera, se hace necesario apuntar todos los procesos hacia ese norte. Ante este escenario, la secuencia didáctica se presenta como la estrategia justa que recoge y engloba los múltiples procesos que exige un conjunto de textos escolares para publicarlos.

Así, se eligió la secuencia didáctica como la mejor estrategia para aplicar a este proyecto: "escribir para publicar" porque es el recorrido de las ideas que van dando un avance mayor tanto en profundidad como en extensión. Los estudiantes partirán desde un punto inicial y al pasar por cada una de las etapas se fortalecerán y, paulatinamente, mejorarán sus desempeños escriturales de manera coherente y progresiva. Gracias a que la secuencia didáctica se organizó a partir de los contenidos de enseñanza de las diferentes disciplinas, donde se exponen los objetivos de competencia que forman parte del proyecto y que, a su vez, hacen parte de los Estándares de Básicos de Competencias del MEN. La innovación se encuentra en la misma publicación de su producción textual. Esta expectativa no es posibilidad del currículo tradicional. Recuérdese que publicar no es una competencia planteada en los Estándares Básicos de Competencias. Gracias a los currículos no lineales se puede hacer del quehacer académico una aventura que involucre al estudiante desde todas sus dimensiones humanas.

La secuencia didáctica "escribir para publicar" es el "pretexto" que facilita la motivación para este grupo de estudiantes. En la descripción del problema se expuso ampliamente la dificultad que presenta esta población para producir texto escrito. Escribir para publicar es contextualizar el problema, es hacerlo real y, al hacerlo real, se hace auténtico, por lo que el estudiante al adaptarse a este fin, responde a las condiciones dadas por esa necesidad. El estudiante está potencializado en el lenguaje debido es portador de un condigo lingüístico y está inmerso en una cultura. Aquí se facilitan los procesos pragmáticos porque son los que legitiman el hacer, en este caso, le da un horizonte al estudiante. Por eso la secuencia didáctica es el mejor recurso que recoge todas estas consideraciones.

Por otra parte a partir de Camps se considera que la secuencia didáctica se puede concretar en toda una serie de actividades que involucra a todos los estudiantes de forma individual o grupal, para realizar todos los procesos que aportan a la producción y transformación de la escritura en fin al mejoramiento de la misma.
Ahora bien, ¿por qué la necesidad de escribir en la escuela? El propósito de esta pregunta es hacer una aproximación conceptual sobre el proceso de la escritura, para así generar las bases que permitan pensar una estrategia educativa de escritura en la Institución Educativa Manuel Elkin Patarroyo. Para iniciar el desarrollo de esta consideración, se trae el concepto de Ferreiro y Teberosky (1980), citada por Guzmán, Chálela y Gutiérrez donde se entiende la escritura como "el medio perfecto para el desarrollo intelectual del ser humano, ya que, a través de ella, el hombre escribe lo que ha aprendido, reconociendo sus aciertos y errores, siendo capaz de corregirlos".

Interpretando el concepto anterior, es evidente que la escritura se constituye en una actividad "perfecta" para construir el intelecto humano porque es una excelente posibilidad de reconocer los errores. Al encontrarlos escritos en el papel, libres de otra subjetividad, se ofrecen ante su autor como la oportunidad de realimentar su propio decir. Por eso, el texto escrito se devuelve y se repliega sobre el mismo escritor y genera el encuentro consigo mismo convirtiéndose en un choque con su propio yo.

Sin embargo, escribir es una actividad exigente y compleja, y esta característica es una afirmación de todos los teóricos del lenguaje. Para realizar este acto en la escuela es importante tener en cuenta que los estudiantes avanzaron en un proceso lingüístico desde su nacimiento. Esto implicó numerosos procesos que, dentro de una comunidad, son tácitos y se adquieren inicialmente sin rigor académico, estos son: fonéticos, semánticos, gramaticales, semióticos, pragmáticos, posteriormente en la escuela aparecen los escriturales, que conllevan la profundización de los anteriores y aparecen los procesos de sintaxis y de ortografía. Este avance es paulatino y continuo. Precisamente, Ramos corrobora esto cuando señala que: "la escritura es una construcción cultural -y, por tanto, adquirida socialmente- muy útil para elaborar diferentes interpretaciones de la realidad personal, social, cultural, política, científica..., y para comunicar a los demás las propias fantasías e ilusiones, angustias, sentimientos, emociones" (56).

Por esta razón, la escritura en el aula de clase se ubica en el eje central para apoyar todo acto comunicativo. Sin escritura, por elemental que sea, no hay conocimiento, no aparece el pensamiento lógico. Gracias a la escritura, el estudiante puede apreciar sus errores, tiene la oportunidad de encontrarse en ellos y corregirse. La escritura también está en la realidad y según Guzman, Chalela y Gutierrez (2009) 
el lenguaje escrito es más complicado de captar ya que quien lee lo escrito debe imaginar la realidad y ordenarla mentalmente de acuerdo con la intencionalidad del texto, Esta actividad, que es individual, al ser organizada ofrece una realidad despejada para el estudiante y por estar permeada por el otro, lo constituye socialmente. Siempre que se escribe se reproduce lo que otros han escrito. La articulación de todas estas voces, llamada polifonía, es la que le da carácter personal, o sea, su originalidad, aunque la creación de conceptos nuevos es el acto creativo por excelencia. Entonces, y siguiendo Guzman, Chalela y Gutierrez (2009), la escritura se constituye en un proceso individual y a la vez social en la que se configura un mundo y entran en juego saberes, competencias, intereses y está determinado por el contexto en el cual se produce. Es la producción de sentido por medio de signos gráficos y de esquemas de pensamiento para representar y comunicar significados.

Entonces, de acuerdo con Ramos, escribir es "planificar situaciones y actividades de enseñanza y aprendizaje que prevean la toma de conciencia (progresiva) de la existencia de conocimientos específicos ligados a las particularidades de los géneros escritos" (58). Ahora bien, de esta manera se aspira a que el estudiante a través de su producción textual narre sus expectativas y sueños, para esto es importante conocer que, según McEwan y Kieran:

las narrativas son un valioso instrumento transformador: nos permiten comprender el mundo de nuevas maneras y nos ayudan a comunicar nuevas ideas a los demás. Podemos construir mundos en diversas formas. Las narrativas nos permiten descubrir nuevos sentidos asimilando las experiencias a un esquema narrativo. (65).

El estudiante continuamente está narrando: como cuando cuenta el partido de fútbol, la anécdota del día anterior, las circunstancias que rodearon un olvido, etc. Es un acto diario que se hace necesario. Todos los seres humanos son narradores y soñar con un mundo mejor es un propósito real que da autenticidad a la narrativa, es un deseo que involucra una intencionalidad que, a su vez, motiva y condiciona al estudiante a la realización de ese sueño. De todo esto resulta el cambio para el logro de una sociedad pensada y anhelada. Así, se da inicio a los sueños, pues sin ellos no hay evolución.

De esta manera, la construcción gramatical que hace el escritor en virtud del trabajo de escribir, permite que el texto mismo arroje nuevos objetos gramaticales o nuevos contextos que no son producto directamente del escritor, sino de aquel trabajo de ajuste gramatical que venía haciendo. Es decir, el texto mismo produce nuevas realidades. La producción textual y su ejercicio continuo permite transformar la interpretación y la actitud que se hace de la realidad, creando una realidad viviente. Entonces, escribir es crear mejores realidades. Se trata de estructurar el pensamiento que es la antesala para la construcción de sociedades.

Ante la pregunta por cómo se concibe el papel de la escritura en la educación media, se dice que esta es fundamental para los procesos académicos de los estudiantes, teniendo en cuenta su relación con las otras habilidades comunicativas. Así lo señala el Ministerio de educación nacional en los lineamientos curriculares dela lengua castellana Si bien, el objetivo apunta al desarrollo de una tradición lectora que aporte a la comprensión, interpretación y disfrute del texto literario, también se debe estimular la capacidad productiva de los estudiantes, es decir, estimular y propiciar la escritura con intención literaria: cuentos, sociodramas, poemas, ensayos, etc. De tal forma que puedan expresar sus formas particulares de sentir, ver y recrear el mundo, a la vez que desarrollen su producción escrita, teniendo en cuenta que el texto literario aporta al mejoramiento de capacidades expresivas, imaginativas y cognitivas de los estudiantes.

Sin embargo, y a pesar de que en las dos últimas décadas, la reforma educativa intenta que los procesos de enseñanza aprendizaje se soporten sobre el "discurso", entendido este último como "texto en contexto" aún no se alcanza en su totalidad. Para el docente, lo que se pretende con la producción textual de los estudiantes, en muchos casos, es mejorar la ortografía, la caligrafía, la gramática. Al respecto, Cassany dice: "tanta obsesión por la epidermis gramatical ha hecho olvidar a veces lo que tiene que haber dentro: claridad de ideas, estructura, tono, registro, etc" (15). El docente continúa pidiendo prácticas de escritura que solamente buscan dar respuesta a las preguntas solicitadas desde una lectura, encontrar la idea principal y las secundarias, tomar apuntes, hacer resúmenes, realizar tareas $y$, de esta manera, el estudiante cumple con sus deberes desde una actitud pasiva. Es claro que no hay espacio para el debate y la reflexión.

Los docentes argumentan que se realizan mesas redondas para que el estudiante tenga la oportunidad 
de expresar con libertad sus dudas e ideas, pero son pocos los estudiantes que lo asumen, primero, porque el estudiante muchas veces "no tiene que decir" $\mathrm{y}$, segundo, porque el temor a la burla o al ridículo frente a sus compañeros restringe el debate. Cuando el estudiante se ve en la necesidad de escribir en el correo y lo hace brevemente y apoyado en los emoticones o, cuando quiere expresar congratulaciones acude a la web y encuentra toda una gama de textos que él elige dando solución a su necesidad sin tener que realizar mayor esfuerzo mental para obtenerlo. De esta manera, se observa que la búsqueda de sentidos es esquiva en la práctica de la escritura y en el aula misma.

Es precisamente a la escuela, a la que le compete ocuparse de esta labor, a la que le subyacen un conjunto de procesos semióticos y pragmáticos que habrán de desarrollar las habilidades y destrezas escriturales en sus estudiantes, guiados por docentes competentes que, desde la investigación, logren abordarlas de manera interdisciplinaria, pues en todas las áreas del conocimiento las competencias ciudadanas, la constitución política y el énfasis en los deberes y derechos que le permiten fortalecer en su práctica cotidiana la práctica de los valores loables que darán cuenta de su ser, como proyecto de transformación cultural.

El estudiante ha venido haciendo una lectura semiótica desde la infancia, ha leído rostros, acciones, eventos, ha leído a la naturaleza, ha hecho lectura de símbolos, señales e iconos y su construcción se continúa y se profundiza con la lectura del código lingüístico como única posibilidad de realizar los procesos de producción textual escrita. Una vez hecha esta precisión se hace necesario escribir a partir de una lectura. El docente, en grado once, tiene preferencia por los textos argumentativos, además, que los estándares lo así lo prescriben. $\mathrm{Al}$ respecto, Pérez et al. Afirman que:

solo las personas que vibran con la lectura pueden descubrir que leer es una oportunidad constante de aprendizaje y crecimiento, pues a través de ésta, descubrimos el pensamiento de otros, entendemos la divergencia y ampliamos nuestros horizontes. En el caso de los docentes que trabajamos con los sectores desfavorecidos, cuyos estudiantes no tienen la oportunidad de viajar y tener acceso a la información que va más allá de lo que comunica la televisión, el gusto por la lectura es una de las herramientas más importantes que les podemos brindar, pues a través de esta podrán desarrollar su pensamiento, enriquecer sus conocimientos y ampliar su visión del mundo y la vida. (42).

En consecuencia, elegir un corpus de lecturas que sean de interés para los estudiantes se convierte en un reto y para asumirlo es necesario conocer sus gustos. Este reto genera otro más desafiante: el hecho de que as niñas tienen sus preferencias y los jovenes otras diferentes. Es más, al interior de los géneros tampoco es que sea homogéneo el gusto por los temas. Así que el docente acude a sus habilidades comunicativas; el docente, ante todo, es un excelente comunicador, ese lenguaje paralingüístico se hace oportuno y urgente en este contexto con el fin de alcanzar acuerdos, en busca de un efecto favorable en sus receptores.

Frente a la pregunta¿para qué escribir? Son diversas las razones que se pueden tener para ello. Se escribe inicialmente, y de manera inconsciente, aproximadamente a la edad de seis años, precisamente para aprender a hacerlo, posteriormente con el propósito realizar los aprendizajes en todas las áreas del conocimiento. Entonces, se escribe para describir, para exponer, interpretar, argumentar y proponer, finalmente, se escribe para comunicar; desde una nota o un mensaje, una carta, una excusa, una petición, pero también puede ocurrir que se escribe para uno mismo. Cuando se escribe para uno mismo, no necesariamente es para publicarse, también se escribe porque se quiere decir algo, Zambrano (1934) se pregunta:

¿por qué escribir? pero lo inmediato, lo que brota de nuestra espontaneidad, es algo de lo que íntimamente nos hacemos responsables, porque no brota de la totalidad íntegra de nuestra persona; es una reacción siempre urgente, apremiante. Hablamos porque algo nos apremia y el apremio llega de fuera, de una trampa en la que las circunstancias pretenden cazarnos y la palabra nos libra de ello. Por la palabra nos hacemos libres, de la circunstancia apremiante e instantánea. Pero la palabra no nos recoge, ni por tanto, no nos crea y, por el contrario, el mucho uso de ella produce una disgregación; vencemos por la palabra al momento y luego somos vencidos por él, por la sucesión de ellos que van llevándose nuestro ataque sin dejarnos responder. Es una continua victoria que al fin se transmuta en derrota y de esta, derrota íntima, humana, no de un hombre particular, sino del ser humano, nace de la exigencia del escribir. Se escribe para reconquistar la derrota sufrida siempre que hemos hablado largamente. (Zambrano 1). 
Ante esta posición, se comprende que el ser humano vive una lucha interior que, eventualmente, se exterioriza para después nuevamente interiorizarse. En el proceso de esa lucha, el hombre paulatinamente se construye. En esa construcción que solamente termina con la muerte, el hombre llega a la profundidad de su ser, pero lo que tuvo que recorrer largos caminos en el exterior, o sea en la otredad. Ésta es una buena razón para publicar, ese devenir del lenguaje, esa lectura de sus mismos textos, favorece el encuentro con el yo y, en ese encuentro, el estudiante se reconoce a sí mismo. Esta es la dinámica necesaria de retroalimentación para que los estudiantes avancen.

Sobre la evaluación de la escritura en la educación media, el MEN, a través del decreto 1290 de abril de 2009, ha implementado el sistema de evaluación para las instituciones educativas del sector. Los apartes de más importancia en ésta evaluación son el reconocimiento de ser una herramienta que ofrece información y da cuenta de todo el proceso educativo, no solo de los estudiantes, sino también de los docentes y de la institución en general. Desde este marco, se tienen en cuenta dos tipos de evaluación: desde la función y desde los agentes. La primera es la evaluación diagnóstica, la evaluación formativa, que según el MEN en las Fundamentaciones y orientaciones para la implementación del decreto 1290 :

es una de las actividades que hacen parte y se desarrollan dentro del proceso formativo que se adelanta en la institución escolar con la cual no solamente aprende el estudiante, sino que especialmente lo hace el maestro, porque a partir de ella es que se debe visualizar, organizar y planificar su trabajo de enseñanza. (23).

Finalmente, la evaluación sumativa, que equivale a la heteroevaluación, la autoevaluación y la co-evaluación. No obstante, es importante detenernos aquí para precisar que la evaluación formativa es la que tomará más tiempo, ya que ha de hacerse durante todos los procesos y se distingue porque carece de valoración cuantitativa, lo que la convierte en un proceso continuo, flexible, apoyado en la constante retroalimentación, pues sin esta es probable que el estudiante persista en la comisión de los mismos errores. Esta se hace entre docente y el estudiante, y podría darse también entre estudiante-estudiante y estudiante-acudiente, o padre de familia. Esta retroalimentación es personal y es el momento cumbre del aprendizaje, en el que se puede dar la tan esperada reflexión. Tal como lo expresa Shepard:

es insuficiente que los maestros simplemente den una retroalimentación respecto de sí las respuestas son correctas o incorrectas. En vez de ello, para facilitar el aprendizaje, es igualmente importante que la retroalimentación esté vinculada explícitamente a criterios claros de desempeño y que proporcione al estudiante estrategias de mejoramiento. (19).

En este encuentro bilateral, el docente escucha atentamente al estudiante, conoce y evidencia el avance de su proceso, hace un acercamiento puntualy preciso de las debilidades y fortalezas del estudiante. En este escenario se da una valiosa oportunidad para destacar las habilidades que se fortalecen en los aciertos o, en su defecto, corregir los desaciertos. Todos los procesos inmersos en el acto escritural estarán atendidos o supervisados bajo una mirada holística. Al respecto, Sacristan y Pérez Gómez afirman que "este conocimiento global requiere comunicación abierta con él, comprender sus problemas, circunstancias, su trabajo escolar" (34), que no excluirá ningún proceso dentro de la multiplicidad de dimensiones que subyacen al acto comunicativo. De esta manera, se está comprobando la constante comprensión que el estudiante va logrando.

Con esta fundamentación teórica se considera que la evaluación formativa, de acuerdo con esta investigación, es el proceso que requiere de un docente dado a la comunicación asertiva, que sea consciente de que el eje central del acto pedagógico es el acto comunicativo. Para esta evaluación se hizo uso de la rúbrica, entendida como una matriz de verificación que, desde una gama de criterios, permite conocer dónde se encuentra el estudiante sin que necesariamente se haga uso de la valoración numérica, como herramienta facilitadora. En ella, se encuentran los objetivos o metas del aprendizaje que deben estar bien definidos y visibles. Nuevamente, Shepard expone al respecto:

cuando los maestros ayudan a los estudiantes a entender e internalizar los estándares de excelencia de una disciplina -es decir, aquello que hace que un trabajo de historia o una explicación matemática sean buenos- les ayudan a desarrollar la conciencia metacognitiva de aquello a lo que necesitan prestar atención mientras escriben o resuelven un problema. (25). 


\section{Sistematización de la experiencia}

A continuación, se realiza la descripción de la experiencia, teniendo como eje los encuentros entre maestra y estudiante. Aquí se presenta cómo se llevó a cabo la actividad, las temáticas tratadas y la respuesta de los estudiantes.

\section{Fase de apertura: buscando los caminos de la escritura.}

El anuncio: "estudiantes, ¡vamos a publicar, nuestros escritos!"

El docente conocedor de las falencias que sus estudiantes presentan para la producción de textos los motivó y les presentó la posibilidad de hacer un libro, con sus relatos, un libro con treinta autores. Para ello, les contó de su quehacer como estudiante de maestría y de su requisito para titularse.

Preguntó a sus estudiantes si querrían participar en este proyecto. Solamente se negaron dos estudiantes, quienes al cabo de pocos minutos se unieron a la mayoría para participar en la elaboración de dicho libro.

El docente, con los estudiantes, delimitó, el problema central: ¿cómo hacer un libro? Esta pregunta fue instalada en el tronco del árbol y todas las demás preguntas que surgieron a partir de ésta, se instalaron en las ramas de este. En la raíz se pusieron los orígenes del problema. Los estudiantes se mostraron inquietos y animados.

Ellos desarrollaron los siguientes puntos para la elaboración del texto propuesto:

- Dejarlo en reposo dos días.

- Leerlo nuevamente corregir y añadir lo que se crea conveniente.

- Dejarlo en reposo cuatro días.

- Nuevamente leerlo, corregir y añadir.

- Leerlo a otra persona y apuntar sus comentarios.

Gramatrimonios: cada uno de los veintinueve estudiantes sacó de un recipiente un papelito en los que aparecían dos preposiciones. El estudiante acudió a cada uno de sus compañeros y le formuló una pregunta cualquiera. El estudiante cuestionado respondió con una de las preposiciones obtenidas. En total, cada estudiante formuló 60 preguntas y escuchó 60 veces preposiciones, muchas de ellas, en repetidas ocasiones. La actividad inició con prevención, pero en la medida en la que se avanzó, los estudiantes formularon preguntas perspicaces y ante esta situación, la actividad se tornó divertida.

La actividad posterior fue una producción escrita donde se solicitó a los estudiantes la personificación de preposiciones en un relato fantástico. Los estudiantes de las filas de la derecha escribieron el sujeto cualquiera para una oración y las filas de la izquierda un predicado cualquiera. En seguida, se les pidió a los estudiantes de las filas de la derecha que buscaran un compañero de su elección y preferencia en las filas de la izquierda. Reunieron las mitades de la oración, sujeto y predicado, y formaron oraciones que ellos ajustaron de acuerdo con la concordancia requerida en cuanto a género y número. Las siguientes, son algunas de las oraciones que surgieron:

- Todas las redes sociales del mundo explotaron en carcajadas que iluminaron los rostros del siglo XXI.

- Mi querida Colombia trapea cada vez que se siente sola.

- Los valores que aprendo en la casa construyeron el castillo.

- Los mejores deportistas son fuertes como los tigres y astutos como los lobos.

- Los amores del Manuel Elkin Patarroyo corrieron y saltaron. Los celulares Samsung gritaron con todas sus fuerzas.

El siguiente encuentro se denominó: ¡lo que escribimos es literatura, la literatura es la posibilidad de un mundo mejor! Este se realizó a partir de las siguientes actividades:

- Destrucción mental de esta realidad.

- Reconstrucción mental de una nueva realidad.

Estas actividades se orientaron desde las siguientes condiciones: leyes, normas, en reglamentos, horarios, espacios, deportes, juegos, relaciones sociales

En este encuentro los estudiantes dicen una palabra sin darse el tiempo de pensarla, es un intento llamado: "huida de la conciencia". Se organizaron equipos de cinco estudiantes y sin darles tiempo de pensarlo, se les pide un sustantivo. Después, cada uno de ellos construye una imagen que incluya el sustantivo elegido. Las imágenes son el producto del inconsciente humano. Al tener las cinco imágenes, o frases, ellos eligieron la mejor.

El docente organizó a los estudiantes en parejas. El estudiante A, se acuesta sobre el papel y el 
estudiante B delinea o bordea su cuerpo con un lápiz. En seguida, se cambian los roles y a la inversa, sobre otro papel se repite el delineado. De esta manera, se obtuvo el croquis o perfil de todos y cada uno de los estudiantes. Sobre estas siluetas los estudiantes escribieron las palabras que eligieron para las diferentes partes y órganos de sus cuerpos. Finalmente, los estudiantes hicieron una ronda para observar el perfil y leer las palabras que identifican a los compañeros. La clase se tornó interesante porque los estudiantes quisieron imponer su identidad a través del lenguaje subjetivo, que terminó evidenciando sus gustos, sus hábitos y en algunos sus miedos.

En este primer momento de trabajo, se hizo énfasis en la motivación. Los estudiantes estuvieron receptivos y manifestaron interés en las actividades, en consecuencia, se motivaron. En cada encuentro de esta fase se divirtieron, hicieron bromas, el aburrimiento ante la clase de español desapareció. Cumplieron con la realización de las actividades, se minimizó la solicitud de permisos para ir al baño o cualquier otro pretexto para salir del salón. Desapareció la evasión de clase. Se mostró la concentración en las actividades que así lo requerían.

\section{Fase de desarrollo: somos escritores.}

A partir de las actividades desarrolladas en la primera fase, se generó el insumo que permitió la escritura de textos auténticos por parte de los estudiantes. Es así, que tanto docente como estudiante, al recorrer las posibilidades que nos brinda la escritura, partieron de la propia experiencia, la historia de vida, para crear textos llenos de sentido y significado.

Para la elaboración de las biografías hubo gran empeño. Cada uno se interesó por una buena producción textual, trajeron fotografías de su infancia y de sus padres. Su defensa de la identidad fue notable por la individualidad con que se realizó esta actividad, sobre todo en los varones; las niñas estuvieron acompañadas entre sí para esta actividad, no hubo copia. El docente leyó algunas biografías con el permiso de sus autores. Esta actividad solamente tuvo cuatro estudiantes que postergaron su producción textual escrita y no la terminaron.

Segundo paso: de mi propia experiencia a la realidad global. Esta fase comprendió tres avances en la producción escrita y la entrega del producto final. Los estudiantes conocieron con anterioridad la fecha de entrega de cada uno de los avances y sus características requeridas. Para este primer avance, se les solicitó que hicieran el intento de cambiar la realidad. Aunque fue la fase crítica, finalmente se logró que escribieran las dos o tres páginas para publicar; no obstante, la idea de obligatoriedad no desapareció en todos los estudiantes durante esta fase. Como resultado final, se apreció en la narrativa de los estudiantes su deseo por una sociedad mucho más justa y libre, la desaparición de la guerra y de la corrupción.

\section{Fase de cierre: lectores de nuestros escritos.}

La metacognición quedó reducida al encuentro personal del estudiante con el docente, cuando se hizo entrega de su rúbrica. El docente preguntó al estudiante ¿qué aprendió?, ¿qué competencias mejoró?, ¿qué competencias corrigió?, ¿a qué conclusiones llegó? Ante tales preguntas, la mayoría de los estudiantes intentaron justificar su desinterés durante la segunda fase. Tuvieron la oportunidad de hablar sin la presión del grupo, en la medida en que docente favorecía una interacción basada en la confianza y la informalidad. Las preguntas del docente fueron particulares de acuerdo con el desempeño del estudiante. Todos los estudiantes, excepto seis, mostraron arrepentimiento por la falta de compromiso con sus deberes de producción textual escrita. Se pudo observar que estos estudiantes, en el afán de entregar el producto final, no fueron conscientes de la necesidad y de la importancia del proceso; sin embargo, se sintieron satisfechos con su texto escrito a la carrera.

\section{Conclusiones}

Finalmente, se llegó a las siguientes conclusiones:

a. Se diseñó, construyó y aplicó una secuencia didáctica en el grado once, que se desarrolló en 14 encuentros académicos, equivalentes al último periodo escolar del año, cada uno de 120 minutos. La secuencia se realizó en tres fases.

- En la primera fase se negoció y planeó con los estudiantes un proyecto que contribuyera al mejoramiento de las habilidades de escritura y se fijó como meta la elaboración un libro para ser publicado.

- En la segunda fase el avance fue lento y los estudiantes volvieron a asumir una actitud de obligatoriedad frente a la actividad de la escritura. Frente a las clases de la segunda fase, el avance no fue totalmente satisfactorio; sin 
embargo los textos escritos por los estudiantes dieron cuenta de sus sueños y expusieron sus deseos por el logro de una Colombia justa, sin guerra ni corrupción.

- En la tercera fase se evidenció, tardíamente, el renacer de un interés por sus producciones textuales.

Esto permite concluir que la secuencia didáctica implementada resultó ser una estrategia fundamental para la producción textual escrito. También:

b. Se logró identificar que, en el marco de los procesos escriturales, los estudiantes de grado once, de la Institución Educativa Manuel Elkin Patarroyo, presentan gran dificultad para crear e inventar una nueva realidad a través de sus sueños; sin embargo, desean tener un mundo más justo, equitativo y libre, aunque lo consideran como una realidad inalcanzable.

c. El hilo conductor facilitado por la secuencia didáctica favoreció, inicialmente, las actividades realizadas. Se evitó la dispersión de las ideas y se le dio sentido a todos los quehaceres académicos que se dieron, tanto en los estudiantes como en los del docente.

d. Se diseñó una secuencia didáctica como estrategia para el desarrollo de prácticas auténticas de escritura logrando determinar que la producción textual tiene influencia en todos los procesos de aprendizaje y construcción humana. Por esta razón, se hace necesario que el estudiante escriba y que, al escribir desde su subjetividad como dimensión real, el proceso se vuelva auténtico.

e. Durante el proceso de la metaevaluación, el estudiante, junto con el docente, desarrolló un proceso de reflexión que se dio a partir del desarrollo de las todas las actividades, del avance presentado en las habilidades de producción escrita y de su misma producción escrita. Este momento fue crucial para el estudiante porque aceptó y comprendió la necesidad de la escritura como un proceso de comunicación de las estructuras sociales.

f. Los estudiantes tuvieron la oportunidad de reencontrarse consigo mismos cada vez que acudieron a su texto escrito con el fin de modificarlo porque así fue establecido por la secuencia didáctica. Este reencuentro fue una posibilidad para corregir, comprender y analizar, a lo que se le dio sentido mediante una retroalimentación.

\section{Bibliografía}

Blackmore, Susan. Conversaciones sobre la conciencia, 2010. Barcelona: Paidós. Impreso.

Calderón-Perilla, C. (2015). Una Secuencia Didáctica como experiencia para el desarrollo de prácticas de escritura auténtica en el grado once cuatro de la institución educativa Manuel Elkin Patarroyo de Girardot Cundinamarca. Ibague: Universidad del Tolima.

Camps, Anna. Secuencias didácticas para aprender a escribir. Serie didáctica de la lengua y la literatura, 2003. Barcelona: Gráo. Impreso.

Cassany, D. (1995 ). La cocina de la escritura. https://media.utp.edu.co/referencias-bibliograficas/uploads/ referencias/libro/287-la-cocina-de-la-escriturapdf-2vEUo-libro.pdf

Delval, Juan. Crecer y pensar: la construcción del conocimiento en la escuela, 1991. México: Paidós. Impreso.

Ferreiro, Emilia y Teverosky, Anna. Los sistemas de escritura en el desarrollo del niño, 1991. México: Siglo XXI. Impreso.

Guzman, Martha , María del Socorro Chalela y Angela Gutierrez. Universidad Santo Tomas. 2009. 16 de 9 de 2018. <http://soda.ustadistancia.edu.co/enlinea/ mariachalelaDesarrollo\%20de\%20la\%20lectura \%20 y\%20escrit_mariachalela-1/proceso_de_aprendizaje_de_la_lectura_y_la_escritura.html $>$.

Hernández-Sampieri, Roberto; Baptista, Pilar y Fernández, Carlos. Metodología de la Investigación, 2010. México: McGraw-Hill. Impreso.

MacEwan, Hunter y Kieran, Egan. La narrativa en la enseñanza, el aprendizaje y la investigación, 2005. Buenos Aires: Amorrortu. Impreso.

Mercado Vargas, Horacio y Mercado Vargas, Litzajaya. Necesidad de una revolución educativa en México, 2010, http://www.eumed.net/libros-gratis/2010f/885/index. htm

Ministerio de Educación Nacional (MEN). Estándares básicos de competencias en lenguaje, matematicas, ciencias y ciudadanas, 2006. Bogotá: Ministerio de Educación. En línea.

Ministerio de Educación Nacional (MEN). Fundamentaciones y orientaciones para la implementación del decreto 1290 de 2009. Documento No. 11, 2009. Bogotá: Ministerio de Educación Nacional. En línea.

Ministerio de Educación Nacional (MEN). Decreto 1290 de 2009, https://www.mineducacion.gov.co/1621/articles-187765_archivo_pdf_decreto_1290.pdf 
Pérez, Antonio; Ortiz, Marielsa; Borjas, Beatriz y Millán, Zulay. Propuesta didáctica para la enseñanza de la lectura y escritura en la educación básica, 2006. Maracibo: Fe y alegría. Impreso.

Ramos, Joaquín. Enseñar a escribir con sentido. Aula de innovación educativa. 185 (2009): 55-63. En línea.

Sacristán, Gimeno y Pérez Gómez, Ángel. Comprender y transformar la enseñanza, 1992. Madrid: Morata. Impreso.

Shepard, Lorrie. La evaluación en el aula, 2006. México: Instituto Nacional para la Evaluación de la Educación. En línea.
Tobón, Sergio. Aspectos básicos de la formación basada en competencias, 2006. Bogotá: Ecoe Ediciones. Impreso.

Tobón, Sergio; Pimienta, Julio y García, Juan. Secuencias didácticas: aprendizajes y evaluacion de competencias, 2010. México: Pearson. Impreso.

Zabala, Antoni. La práctica educativa: cómo enseñar, 2008. México: Gráo. Impreso.

Zambrano, María. (1934). Por qué se escribe. Lo sagrado en el pensamiento de María, 2012, https://javierbrolo. files.wordpress.com/2012/12/por-que-se-escribe-maria-zambrano.pdf 